\title{
Modular frame trusses of buildings
}

\author{
Viktor Granev ${ }^{1}$, Nikolay Kelasiev ${ }^{1}$, Emil Kodysh $^{1}$, Nikolay Trekin ${ }^{2 *}$ and Ivan Terekhov ${ }^{1}$ \\ ${ }^{1}$ JSC «TSNIIpromzdany», Russian Federation, 127238 Moscow, Dmitrovskoe shosse, bld.46-2. \\ ${ }^{2}$ Moscow State University of Civil Engineering, Yaroslavskoe shosse, 26, Moscow, 129337, Russia
}

\begin{abstract}
The paper describes space-planning and structural concept in source-efficient buildings that provides multiple functions of the rooms and large-span space.The main load-bearing structures of two adjacent storeys are metal trusses with parallel chords between which (between top and bottom chords) intermediate storeys are designed and the space between trusses is occupied by the free plan storeys. Bottom and top chords of the truss resist together with floor structure forming two-storey steel-reinforced concrete unit. To calculate value of deformation capacity for nodal connection a numerical experiment focused on modelling a part of building from solid finite elements has been performed. The results of performed analysis are the average values of stiffness of nodal interface of solid floor slab on corrugated deck and truss chords for finite elements KE 55 of typical layout (of flat finite elements). The obtained average values of stiffness were introduced into structural design of flat finite elements. Taking into account flexibility of floor slab that supported by middle trusses for the given structural concept leads to decreased span bending moments and increased support bending moments by $25 \%$ compared with hinge support of floor.
\end{abstract}

\section{A review of structural concepts for large-span buildings}

Nowadays free floor plan structural concepts are in high demand due to possibility to transform inner space of the floors through the whole life-cycle of the building $[5,8]$. These are the main structural concepts that provide necessary flexibility of planning space:

- the use of steel beams in floor structures [4];

- the use of extended column grid on the top storey [13];

- the use of "comb structures" and "bearing storeys" $[2,3,10]$;

- arrangement of the storeys in the roof-truss space [6].

The latter is considered to be the efficient and universal structural concept that can be applied in the buildings of different purpose. It is this idea that became the base for spaceplanning and structural concepts in source-efficient buildings. This concept provides multiple functions of the rooms and large-span space $[9,12]$. Commercial efficiency of the buildings is the result of doubled square and minimal costs when using standard structures.

The mentioned above buildings can be multi-storey civil buildings (fig. 1, a) as well as industrial ones (fig. 1, b) [13].

\footnotetext{
* Corresponding author: otks@yandex.ru
} 
The main load-bearing structures of two adjacent storeys are metal trusses with parallel chords between which (between top and bottom chords) intermediate storeys are designed and the space between trusses is occupied by the free plan storeys. Bottom and top chords of the truss resist together with floor structure forming two-storey steel-reinforced concrete unit. Overall dimension of the truss is determined from the specified storey height. The floor structure can be solid and made of precast concrete T-slabs.

The paper considers performance of solid floor structure with corrugated deck [15, 20] placed on the bottom flange of I-beam that is a truss chord (fig. 2). To provide required floor stiffness in vertical flat area its continuity is designed by means of reinforcement over top flange of I-beam (pos. 3, fig. 2).

The study how truss chords jointly work with solid floor structure on corrugated deck required additional research.

a)

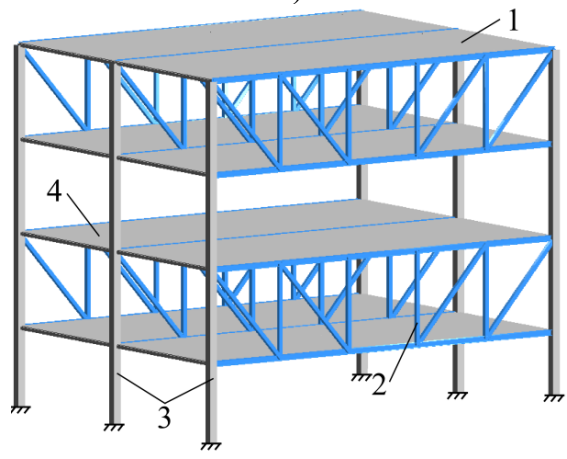

b)

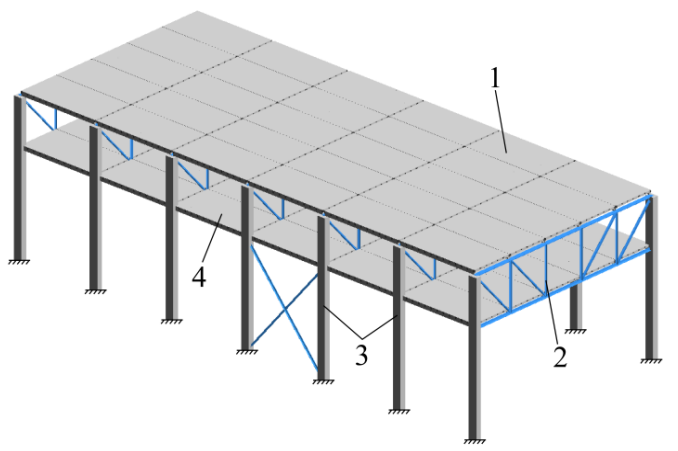

Fig. 1. Fragments of spatial models of the buildings with open plan floors

1 - covering; 2 - steel truss; 3 - columns; 4 - floor structure; $a$ - multi-storey public building; $b$ - one-storey industrial building with additional storey
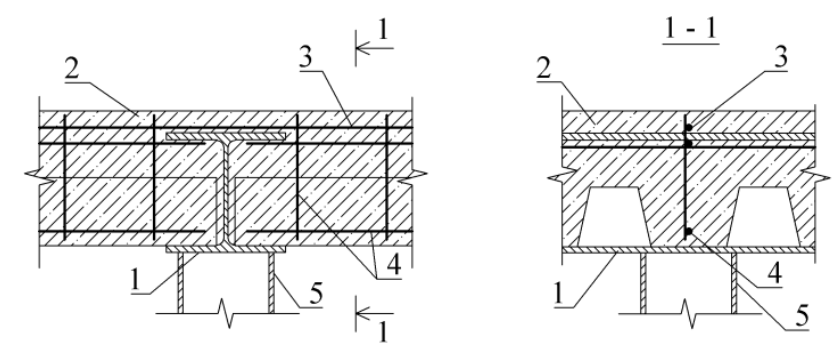

Fig. 2. Nodal interface of solid floor slab on corrugated deck and truss chords

1 - truss chord; 2 - solid slab; 3 -reinforcement over top flange of I-beam; 4 - reinforcement frame; 5 - truss post

\section{Numerical experiment research of actual performance of module with the use of solid finite elements}

When calculating spatial structural diagram of a building, distribution of horizontal stresses between vertical elements (trusses, support pillar) depends mainly on floor structure stiffness in its own flat area that depends on stiffness of single members and strain capacity of the connection between them $[1,11,16,21]$. To account strain capacity of supporting node of solid floor slab on truss chords, one introduced the coefficients that characterize 
strain capacity of supporting zone in floor slab [17-19]: coefficient of shear stiffness $C_{s h}$, coefficients of linear stiffness $C_{x}, C_{y}, C_{z}$ and coefficient of tangent accelerator $C_{\varphi}$.

Coefficient of shear stiffness $C_{s h}$ is equal to the ratio of shearing force applied along joint $Q$ to slab flange shear with respect to the core of metal truss chord $\delta: C_{s h}=Q / \delta$.

Coefficient of linear stiffness is equal to the ratio of direct stress applied crosswise of joint $N$ to the distance between slab flange and core of truss chord: $C_{x}=N_{x} / \Delta_{x} ; C_{y}=N_{y} /$ $\Delta_{y} ; C_{z}=N_{z} / \Delta_{z}$.

Coefficient of tangent accelerator stiffness is equal to the ratio of moment $M$ in the node to the correspondent angle $\varphi$ of mutual rotation of axes in this node: $C_{\varphi}=M / \varphi$.

The most accurate values of node deformation capacity are determined in experiments [14]. To calculate value of deformation capacity for nodal connection a numerical experiment focused on modelling a part of building from solid finite elements has been performed.

Numerical research was carried out for a module (fig. 3) consisted from two spans with floor structures in program LIRA-SAPR 2013 [7]. The parameters of the given module are: truss span $-15 \mathrm{~m}$, column space $-6 \mathrm{~m}$, floor height $-3 \mathrm{~m}$.

There were two spans in the three-dimensional model for numerical experiment. In real buildings number of trusses depends on length of temperature block, therefore a coefficient for deformation module was introduced into numerical experiment. The coefficient is based on the empirical calculations for columns and trusses of an end frame and is equal to number of replaced building frames.

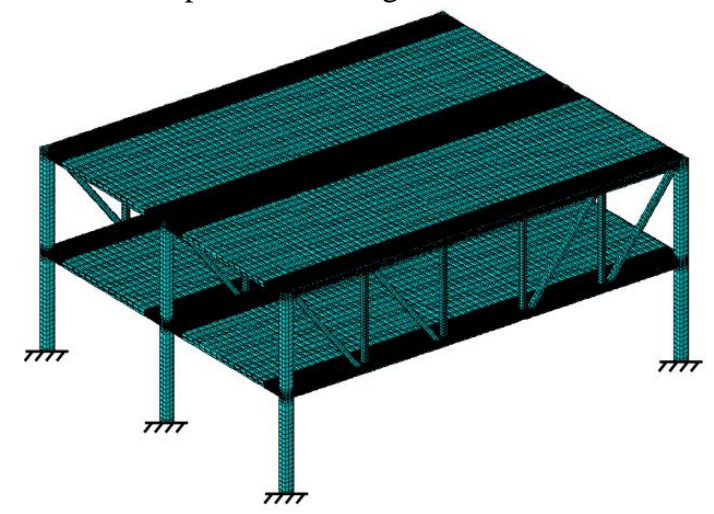

Fig. 3. Spatial model of solid finite elements

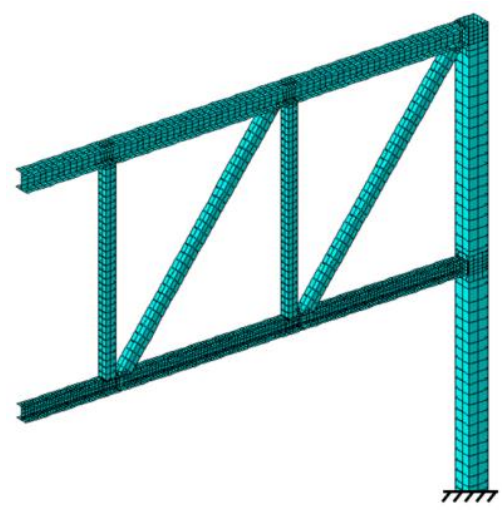

Fig. 4. A fragment of truss structure

The structural members in the three-dimensional design model were modeled in the following way: metal trusses - by means of plate elements (fig. 4); solid floor slabs - by means of solid finite elements; corrugated deck - by means of plate elements.

The supporting section of solid floor slab on the truss had finer layout.

\section{Analysis of numerical experiment results}

Determination of reactions in connections produced by singular shear action, singular displacement and singular angle of rotation was considered under vertical stress $10 \mathrm{kN} / \mathrm{m}^{2}$ on all surface.

The obtained average stifness coefficients were introduced in structural design from flat finite elements. In this structural design connection stiffness Rx, Ry, Rz are assigned for FE 55 as well as rotation relative stiffness of truss Rux, Ruy, Ruz. In the given structural design connection of solid floor with truss is semirigid. 
To compare stresses three design concepts were analyzed: with hinged, semirigid and rigid connections. In each concept 5 sections on supporting structure (№1-№5) and 5 sections in the middle of span (№6-№10) were selected (fig. 5). The comparison results are shown in the tables 1 and 2 .

On the basis of the results of numerical experiment it was determined that taking into account flexibility of floor slab for the given structural concept (fig. 2) leads to decreased span bending moments of and increased support bending moments by $25 \%$ compared with hinge support of floor.

Due to low values of stiffness coefficients for solid floor supported by end trusses it is possible to regard this nodal connection as the hinge one.

Table 1. Comparison of stresses for top floor structure

\begin{tabular}{|c|c|c|c|c|}
\hline \multirow{2}{*}{$\begin{array}{c}\text { Section } \\
\text { number }\end{array}$} & \multicolumn{2}{|c|}{$\begin{array}{c}\text { Value of stresses My,(kN*m)/m, in dependence } \\
\text { on connection type between solid floor and truss: }\end{array}$} & $\begin{array}{c}\text { Difference of stress } \\
\text { value in hinge and } \\
\text { semirigid connections, } \\
\text { \% }\end{array}$ \\
\cline { 2 - 4 } & hinge & semirigid & rigid & 23.7 \\
\hline 1 & 5.59 & -1.44 & -24.09 & 21.3 \\
\hline 2 & 6.38 & -1.89 & -32.36 & 25.3 \\
\hline 3 & 5.38 & -1.51 & -21.90 & 21.0 \\
\hline 4 & 6.62 & -2.44 & -36.62 & 23.9 \\
\hline 5 & 5.44 & -1.47 & -23.49 & 25.6 \\
\hline 6 & 52.59 & 43.89 & 18.54 & 25.7 \\
\hline 7 & 51.47 & 42.95 & 18.30 & 25.3 \\
\hline 8 & 51.25 & 42.94 & 18.46 & 25.3 \\
\hline 9 & 51.76 & 43.51 & 19.14 & 25.1 \\
\hline 10 & 51.71 & 43.49 & 18.98 & \\
\hline
\end{tabular}

Table 2. Comparison of stresses for bottom floor structure

\begin{tabular}{|c|c|c|c|c|}
\hline \multirow{2}{*}{$\begin{array}{c}\text { Section } \\
\text { number }\end{array}$} & \multicolumn{2}{|c|}{$\begin{array}{c}\text { Value of stresses } \mathbf{M y},(\mathbf{k N} * \mathbf{m}) / \mathbf{m}, \text { in dependence } \\
\text { on connection type between solid floor and truss: }\end{array}$} & $\begin{array}{c}\text { Difference of stress value } \\
\text { in hinge and semirigid } \\
\text { connections, \% }\end{array}$ \\
\cline { 2 - 4 } & hinge & semirigid & rigid & \\
\hline 1 & 5.56 & -1.64 & -25.67 & 23.1 \\
\hline 2 & 6.55 & -1.93 & -35.71 & 20.1 \\
\hline 3 & 5.35 & -1.4 & -21.66 & 25.0 \\
\hline 4 & 6.5 & -2.47 & -34.36 & 22.0 \\
\hline 5 & 5.38 & -1.34 & -22.00 & 24.5 \\
\hline 6 & 53.98 & 44.28 & 18.47 & 27.3 \\
\hline 7 & 52.00 & 43.35 & 18.54 & 25.9 \\
\hline 8 & 51.22 & 42.85 & 18.4 & 25.5 \\
\hline 9 & 51.22 & 43.04 & 18.87 & 25.3 \\
\hline 10 & 51.07 & 42.95 & 18.74 & 25.1 \\
\hline
\end{tabular}




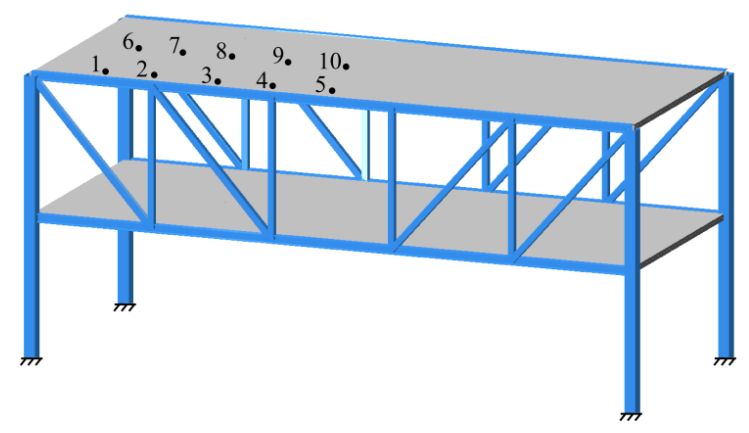

Fig. 5. The scheme of positions of solid floor sections for which the values of stresses $M_{y}$ have been calculated

1-10 - section numbers (for bottom floor the position of the sections is not shown and is considered to be the same as for the top floor)

\section{Conclusions}

1. The results of performed analysis are the average values of stiffness of nodal interface of solid floor slab on corrugated deck and truss chords for finite elements KE 55 of typical layout (of flat finite elements).

2. Taking into account flexibility of floor slab that supported by middle trusses for the given structural concept leads to decreased span bending moments and increased support bending moments by $25 \%$ compared with hinge support of floor.

3. Results of numerical experiment facilitate the application of space-planning and structural concepts of source-efficient buildings with open plan floors and new type of modular load-bearing structures.

\section{References}

1. Baikov V.N., Frolov A.K. Analysis of deformability of nodal interface between girts and columns. Concrete and Reinforced Concrete, no. 2, pp. 26-28. (1978)

2. Biryukov V.V., Zabalueva T.R., Zakharov A.V. Long-Span Multistorey Buildings. Vestnik MGSU. no. 8, pp.58-68. (2011)

3. Biryukov V.V., Zabalueva T.R., Zakharov A.V. Long-Span Multistorey Buildings under Conditions of Dense Urban Development. Industrial and Civil Engineering., no. 11, pp. 46-49. (2012)

4. Corus Construction and Industrial. Steel-framed car parks. 36 p. (2004)

5. Eremeev P.G. Modern steel structures of large-span coverings in unique buildings and structures. Moscow, Moscow, ASV, 333 p. (2009)

6. Glukhovsky A.D. Industrial buildings with floors in roof-truss space. Central Research and Design Institute of Industrial Buildings and Structures "TSNIIpromzdany". Moscow, Stroyizdat, 128 p. (1971)

7. Gorodetsky D.A., Barabash M.S., Vodopyanov R.Yu. Programm complex LIRA-SAPR 2013. Textbook. Edit. by Acad. RAACS Gorodetsky A S. Moscow, Electronic edition, 376 p. (2013)

8. Granev V.V. Scientific and Technical Support for Design of Buildings and Structures. Industrial and Civil Engineering. no. 6, pp. 4-8. (2018) 
9. Granev V.V., Kelasiev N.G., Kodysh E.N., Trekin N.N., Terekhov I.A. Buildings with Open Plan Floors and Integrated Load-Bearing Structures. An ACI Technical Publication. Symposium Volumes. - SP-326: Durability and Sustainability of Concrete Structures (DSCS-2018). American Concrete Institute. pp. 99.1-99.8. (2018)

10. Kanchli N.V. Building space structures. Moscow, ASV, pp. 43-51. (2003)

11. Kholmyansky M.M. Concrete and reinforced concrete. Deformability and strength. Moscow, Stroyizdat, 570 p. (1997)

12. Kodysh E.N., Trekin N.N., Terekhov I.A., Eremeev D.S., Soskov A.A. Improvement of space-planning and structural systems in large-span buildings through the example of parking garages on the steel frame. Academia. Architecture and Construction, no. 3, pp.103-107. (2017)

13. Kodysh E.N., Trekin N.N., Terekhov I.A. One-Storey Industrial Buildings with Operated Areas in Roof-Truss Space. Industrial and Civil Engineering. no. 6, pp. 2831. (2018)

14. Mamin A.N., Trekin N.N. Experimental research on flexibility of nodal interfaces of reinforced concrete structures in industrial buildings. Experimental research on engineering structures. Sumy, pp. 31-32. (1991)

15. Nethercot D.A., editor. Composite Construction. England: London. 243 p. (2003)

16. Torrenti J.M., Pijaudier-Cabot G., Reynouard J.M. Mechanical Behavior of Concrete, ISTE Ltd and John Wiley \& Sons, Inc. 448 p. (2010)

17. Trekin N.N. Flexibility of interfaces in prefabricated floor slabs. Construction materials, equipment, technologies of the XXI century. no. 9, pp. 32-33. (2003)

18. Trekin N.N. The flexibility of the nodal interfaces of precast concrete structures. Vestnik VNIIZHT, no. 6. (2003)

19. Trekin N.N. Recommendations for the calculation of multi-storey building frames taking into account the flexibility of the nodal interfaces of precast concrete structures. Moscow, GUP CzPP Publ., pp. 24-43. (2002)

20. Tusnin A.R. Floors of Multi-Storey Buildings with Steel Frames. Industrial and Civil Engineering. no. 8, pp. 10-14. (2015)

21. Vasilkov B.S., Volodin N.M. Calculation of building prefabricated structures with consideration for nodal flexibility. Moscow, Stroyizdat, 144 p. (1985) 